\title{
Mammillary Body and Fornix Injury in Congenital Central Hypoventilation Syndrome
}

\author{
RAJESH KUMAR, KWANOO LEE, PAUL M. MACEY, MARY A. WOO, AND RONALD M. HARPER \\ Department of Neurobiology [R.K., K.L., R.M.H.], Brain Research Institute [P.M.M., R.M.H.], and School of Nursing [P.M.M., M.A.W.], \\ University of California at Los Angeles, Los Angeles, California 90095
}

\begin{abstract}
Congenital central hypoventilation syndrome (CCHS) is accompanied by reduced ventilatory sensitivity to $\mathrm{CO}_{2}$ and $\mathrm{O}_{2}$, respiratory drive failure during sleep, impaired autonomic, fluid, and food absorption regulation, and affective and cognitive deficits, including memory deficiencies. The deficits likely derive from neural injury, reflected as structural damage and impaired functional brain responses to ventilatory and autonomic challenges. Brain structures playing essential memory roles, including the hippocampus and anterior thalamus, are damaged in CCHS. Other memory formation circuitry, the fornix and mammillary bodies, have not been evaluated. We collected two high-resolution T1-weighted image series from 14 CCHS and 31 control subjects, using a 3.0-Tesla magnetic resonance imaging scanner. Image series were averaged and reoriented to a standard template; areas containing the mammillary bodies and fornices were over sampled, and body volumes and fornix crosssectional areas were calculated and compared between groups. Both left and right mammillary body volumes and fornix crosssectional areas were significantly reduced in CCHS over control subjects, controlling for age, gender, and intracranial volume. Damage to these structures may contribute to memory deficiencies found in CCHS. Hypoxic processes, together with diminished neuroprotection from micronutrient deficiencies secondary to fluid and dietary absorption issues, may contribute to the injury.
\end{abstract}

(Pediatr Res 66: 429-434, 2009)

$\mathrm{P}$ atients with congenital central hypoventilation syndrome (CCHS) often show multiple affective and cognitive problems, including learning and memory deficits, in addition to the classic characteristics of reduced ventilatory responses to $\mathrm{CO}_{2}$ and $\mathrm{O}_{2}$, loss of respiratory drive during sleep, and impaired autonomic regulation (1-5). Brain structural and functional magnetic resonance imaging (MRI) findings suggest that the physiologic and neuropsychological deficits likely develop from hypoxic injury or failed development of multiple structures in brainstem, cerebellar, limbic, and cortical areas (6-12). The injured rostral brain areas include the hippocampus and anterior thalamus, essential structures for selected aspects of memory processing $(13,14)$. Deficits in these two sites appear as both impaired functional MRI signal responses to autonomic and ventilatory challenges (9-12) and

Received February 27, 2009; accepted June 9, 2009.

Correspondence: Ronald M. Harper, Ph.D., Department of Neurobiology, David Geffen School of Medicine at UCLA, University of California at Los Angeles, Los Angeles, CA 90095-1763; e-mail: rharper@ucla.edu

Supported by the National Institute of Child Health and Human Development R01 HD-22695. tissue alterations, as indicated by voxel-based T2-relaxometry and mean diffusivity procedures $(6,8)$.

However, the resolution of these imaging techniques and other logistic issues precluded detailed evaluation of additional structures necessary for memory functions, including the principal output fibers from the hippocampus, the fornix, and target nuclei for those projections, the mammillary bodies. The mammillary bodies and fornix, as well as the mammillothalamic tract and its recipient structure, the anterior thalamus, form components of hippocampal-originated circuitry for short term and spatial memory (15-17). The fornices and mammillary bodies, the latter lying on the ventral brain surface proximal to the skull, are difficult to evaluate with conventional MRI or voxel-based procedures because of their small size and location, and escaped detection of potential morphologic changes in subjects with CCHS.

The integrity of the mammillary bodies and fornix is of interest in subjects with CCHS, because both structures show injury in several conditions characterized by memory deficits, including Wernicke-Korsakoff's syndrome (18), Alzheimer's disease (19), obstructive sleep apnea (20), and heart failure (21); the latter two conditions show less severe but significant memory problems. These conditions result from differing pathologic processes, with alcoholism combined with nutrient deficiencies often associated with Wernicke-Korsakoff's syndrome (22), intermittent hypoxic and inflammatory processes suspected in obstructive sleep apnea (20), and impaired perfusion, inflammation, and hypoxic mechanisms perhaps playing a role in heart failure (21).

The learning and memory deficits found in CCHS suggest that the mammillary bodies and fornices may be injured in a fashion shared by other conditions with memory deficiencies. Our aim was to evaluate mammillary body (MB) volumes and fornix cross-sectional areas in CCHS using high-resolution T1-weighted MRI procedures. We hypothesized that subjects with CCHS would show reduced MB volumes and fornix cross-sectional areas, compared with control subjects.

\footnotetext{
Abbreviations: CCHS, congenital central hypoventilation syndrome; $\mathbf{M B}$, mammillary body; MANCOVA, multivariate analysis of covariance; TIV, total intracranial volume
} 


\section{METHODS}

Subjects. We included 14 CCHS and 31 control subjects in this study (Table 1). The diagnosis of CCHS was based on American Thoracic Society criteria (1), and subjects were recruited through the CCHS family network (http://www.cchsnetwork.org). Six subjects with CCHS were diagnosed with PHOX2B mutations, two were inconclusive, four subjects were not tested, and two could not be reached. Of subjects with CCHS and known PHOX2B mutations, four showed alanine expansions of 20/27, and two of 20/25. We included only subjects with CCHS who required ventilatory support during sleep but not during waking. Subjects with CCHS and other conditions, including cardiovascular or neurologic disorders, or diagnosed Hirschsprung's disease were excluded to avoid confounds with neural injury associated with these conditions. Control subjects were healthy, without neurologic issues, or other problems affecting brain tissue, and were recruited through advertisements at the university campus. All subjects were awake during the entire study (without anesthesia or sedation), and were removed from the scanner to provide rest, if needed.

The study protocol was approved by the Institutional Review Board of the University of California at Los Angeles, and all subjects and their parents/ guardians gave informed written consent/assent before the study.

Magnetic resonance imaging. Brain studies were performed in a 3.0-Tesla MRI scanner (Magnetom Trio; Siemens, Erlangen, Germany). Subjects lay supine, and foam pads were placed on both sides of the head to minimize head motion. Two high-resolution T1-weighted image series were collected using a magnetization-prepared rapid acquisition gradient echo sequence (repetition time $=2200 \mathrm{~ms}$; echo time $=3.05 \mathrm{~ms}$; inversion time $=1100 \mathrm{~ms}$; flip-angle $=10^{\circ}$; matrix size $=256 \times 256$; field of view $=220 \times 220 \mathrm{~mm}$; and slice thickness $=1.0 \mathrm{~mm}$ ). Proton density and T2-weighted images were collected, using a dual-echo turbo spin-echo sequence (repetition time $=8000$ ms; echo times 1 and $2=17$ and $133 \mathrm{~ms}$, respectively; flip-angle $=150^{\circ}$; matrix size $=256 \times 256$; field of view $=240 \times 240 \mathrm{~mm}$; slice thickness $=$ $5.0 \mathrm{~mm}$; and turbo factor $=5$ ) for anatomical evaluation.

Data analysis. Both high-resolution T1-weighted image series were evaluated for motion-related or other artifacts. T1-, T2- and proton densityweighted images were also evaluated for any brain pathology, such as cystic or other mass lesions.

The statistical parametric mapping package SPM5 (Wellcome Department of Cognitive Neurology, UK; http://www.fil.ion.ucl.ac.uk/spm/), MRIcron (23), and Matlab-based (The MathWorks, Inc., Natick, MA) custom software were used to process the brain images, outline mammillary bodies and fornix cross-sections, and calculate MB volumes and fornix cross-sectional areas.

The two T1-weighted image series were averaged to increase signal-tonoise ratio. Averaged images were reoriented into a common space, using a six-parameter rigid-body (nondistorting) affine transformation.

The reoriented images were partitioned into gray matter, white matter, and cerebrospinal fluid probability maps with unified segmentation techniques (24). In gray, white, and CSF probability maps, voxels with a $p$ value $>0.5$ were counted and total intracranial volume (TIV) of each subject was calculated as described elsewhere $(20,21)$.

Using the reoriented images, brain images containing regions of $\mathrm{MB}$ and fornix structures were over sampled $(0.2 \times 0.2 \times 0.2 \mathrm{~mm})$. A single investigator, blinded to subject group assignment, delineated the MB as described earlier $(20,21)$. Briefly, using sagittal and coronal views, the brain midline was determined, and the medial border of the left or right MB was outlined. Superior and inferior MB boundaries were determined with coronal views; successive sagittal slices were used to outline the boundaries of the entire structure, and coronal and axial views were used to confirm boundaries. Delineated voxels in each MB were counted, and volumes of the body on each side were calculated.

Left and right fornix cross-sections were outlined at a level immediately dorsal to the anterior commissure before entry of the fornix columns into the septum, as described elsewhere (21). We calculated fornix cross-sectional areas rather than volumes, because the issue of interest is the extent of potential fiber loss supplying the mammillary bodies, which can be estimated from the cross-sectional areas. It is also difficult to differentiate fornix fibers

Table 1. Demographic and biophysical data of CCHS and control subjects

\begin{tabular}{lccc}
\hline \multicolumn{1}{c}{ Variables } & CCHS $[\mathrm{n}=14]$ & Control $[\mathrm{n}=31]$ & $p$ value \\
\hline Age $($ mean $\pm \mathrm{SD}$, years $)$ & $15.14 \pm 2.27$ & $15.14 \pm 2.36$ & 0.993 \\
Gender (Male:female) & $8: 6$ & $17: 14$ & 0.885 \\
BMI (mean $\left.\pm \mathrm{SD}, \mathrm{kg} / \mathrm{m}^{2}\right)$ & $20.67 \pm 3.80$ & $21.36 \pm 4.30$ & 0.609 \\
\hline
\end{tabular}

$\mathrm{SD}=$ Standard deviation; BMI $=$ Body-mass-index. from axons within the temporal lobe and splenium of the corpus callosum, and into left and right columns after fibers enter the septum. Boundaries of the left and right fornix fibers in the medial-lateral dimension were marked in coronal views; caudal and rostral borders were determined and marked in sagittal views. Both coronal and sagittal boundaries were used to determine the fornix borders in axial views, and axial views were used to outline fornix crosssectional areas. Pixels in each fornix cross-section were counted, and crosssectional areas were determined.

Statistical analysis. We used the Statistical Package for the Social Sciences (SPSS, V 15.0, Chicago, IL) software for statistical assessment. Numerical variables of the demographic and biophysical data were evaluated with independent samples $t$ tests, and categorical values were assessed with $\chi^{2}$. A multivariate analysis of covariance (MANCOVA) was performed to assess MB volume and fornix cross-sectional area differences between groups, with covariates of age, gender, and TIV.

Using Pearson's correlation procedures, we performed correlation analyses between MB volumes with fornix cross-sectional areas and age in the control group and subjects with CCHS. We established intra- and inter-subject reliabilities for MB and fornix cross-sectional area tracings with Pearson's correlation.

Intra and inter-tracer reliabilities. Intra- and intertracer reliabilities were established for outlining MB and fornix characteristics by the initial investigator repeating the outline procedure for both measures in six randomly selected subjects (two subjects with CCHS and four controls). In the same six subjects, another investigator, blinded to the first investigator's measures, also traced both structures. Both intra-tracer (MB: $r=0.96, p<0.001$; fornix: $r=$ $0.92, p<0.001$ ) and intertracer (MB: $r=0.97, p<0.001$; fornix: $r=0.88$, $p<0.001)$ reliabilities for the MB and fornix cross-sections were high.

\section{RESULTS}

Demographic and biophysical variables of subjects with CCHS and control subjects are summarized in Table 1. There were no significant differences in age, gender, or body mass index between subjects with CCHS and control subjects.

Reduced MB volumes and fornix cross-sectional areas in subjects with CCHS were visually apparent on high-resolution T1-weighted images from the individual subjects with CCHS (Figs. 1 and 2). Mean MB volumes and fornix cross-sectional areas for both groups are summarized in Table 2, and indi-

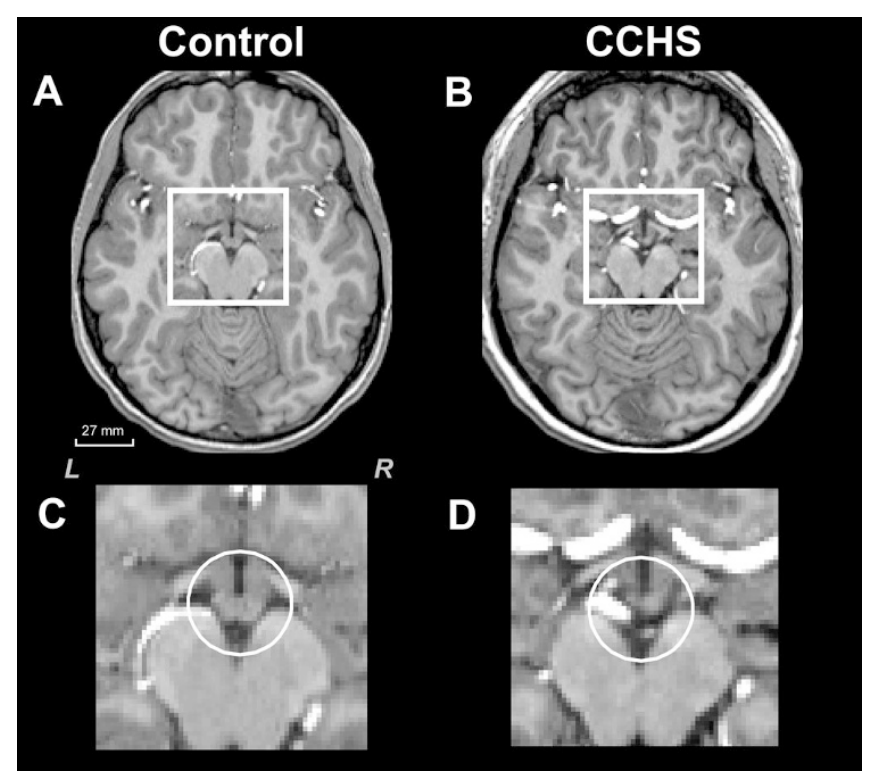

Figure 1. High-resolution T1-weighted images show mammillary bodies in a control $(A: L=$ left, $R=$ right) and CCHS $(B)$ (white rectangles). Brain images $(C)$ and $(D)$ show magnified areas $(\times 2.5)$ within the rectangles of the control $(A)$ and CCHS $(B)$. The right mammillary body in subject with CCHS is smaller, and the left body is much smaller, compared with the control subject ( $C$ vs $D$, white circles). The scale refers to the top panel images. 


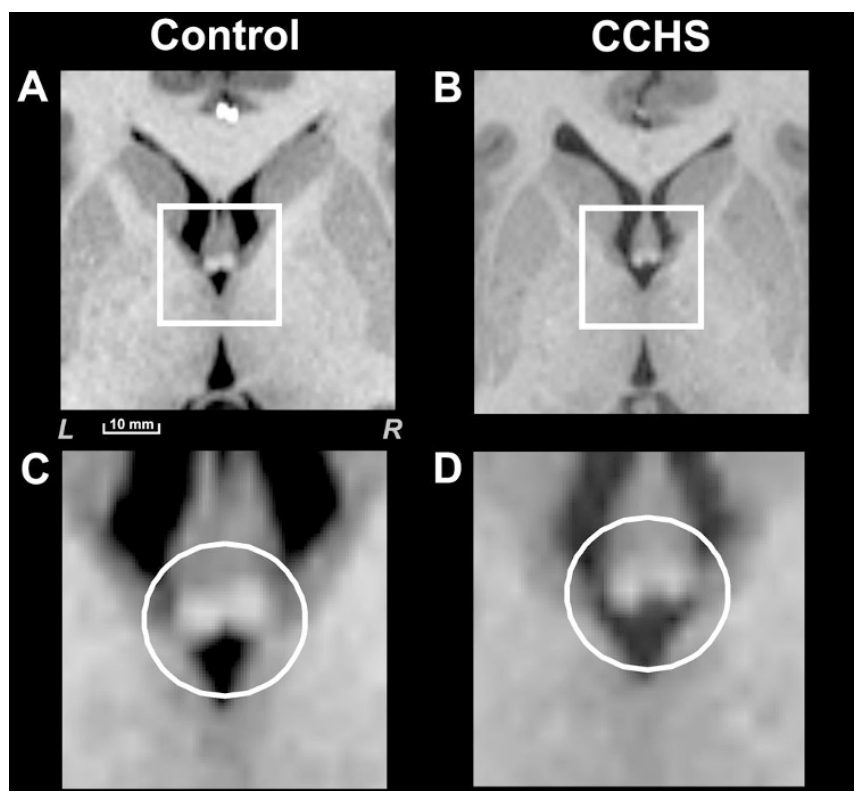

Figure 2. Oversampled high-resolution T1-weighted images show fornix cross-sectional areas in a control $(A)$ and CCHS $(B)$ (white rectangles). Images $(C)$ and $(D)$ show magnified areas $(\times 3.0)$ within the rectangles of the control $(A)$ and subject with CCHS $(B)$. Both left and right fornix crosssectional areas are smaller in the subject with CCHS compared with the control subject ( $C$ vs $D$, white circles). Figure conventions are the same as in Figure 1.

vidual values are displayed on scatter plots (Fig. $3 A$ and $B$ ). Both left and right mammillary bodies showed significantly reduced volumes in subjects with CCHS over control subjects, controlling for age, gender, and TIV (MANCOVA; left, $p<$ 0.001 ; right, $p<0.006$ ). Bilateral fornix cross-sectional areas also significantly differed between the groups after controlling for age, gender, and TIV (MANCOVA; left, $p<0.001$; right, $p<0.005)$. We also partitioned subjects with CCHS and known PHOX2B mutations from the entire CCHS group and made comparable assessments. Again, both left and right MB volumes (MB; left, $77.38 \pm 8.62 \mathrm{~mm}^{3}$ versus $92.35 \pm 13.19$ $\mathrm{mm}^{3}, p<0.005$; right, $79.63 \pm 8.81 \mathrm{~mm}^{3}$ versus $91.66 \pm$ $\left.13.95 \mathrm{~mm}^{3}, p<0.005\right)$ and fornix cross-sectional areas (fornix; left, $7.73 \pm 1.52 \mathrm{~mm}^{2}$ versus $8.41 \pm 1.45 \mathrm{~mm}^{2}, p<$ 0.002 ; right, $7.23 \pm 1.22 \mathrm{~mm}^{2}$ versus $8.32 \pm 1.62 \mathrm{~mm}^{2}, p<$ 0.002 ) showed significant reductions in subjects with PHOX2B mutations versus control subjects, controlling for age, gender, and TIV.

Left MB volumes and fornix cross-sectional areas showed significant correlations with age (MB versus age, $r=0.37$, $p<0.042$; fornix versus age, $r=0.41, p<0.022$ ) in the control group, but on the right side, the equivalent correlations were not significant. Both left and right $\mathrm{MB}$ volumes were positively correlated with corresponding left and right fornix cross-sectional areas in the control group (left, $r=0.60, p<$ 0.001 ; right, $r=0.45, p<0.012$ ).

In the CCHS group, the left MB volumes were significantly correlated with age $(r=0.75, p<0.003)$. Neither left nor right fornix cross-sectional areas showed any significant correlation with age or respective $\mathrm{MB}$ volumes in the CCHS group.

\section{DISCUSSION}

Mammillary body volumes and cross-sectional areas of their major afferent bundles, the fornices, are reduced in children with CCHS. The hippocampus and anterior thalamus, which form principal components of short-term and spatial memory circuitry together with the fornix and mammillary bodies (15-17), earlier showed both structural injury and functional deficits during autonomic and ventilatory challenges in patients with CCHS (6,8-12). The findings of structural injury in brain sites that serve memory functions may provide a basis for a portion of the cognitive deficits in subjects with CCHS, including memory issues (5).

Structural components of learning and memory functions. A set of integrated brain structures, including the hippocampus, anterior thalamus, fornix, and mammillary bodies, serves aspects of memory processing. The mammillary bodies contain two major nuclear groups, medial and lateral nuclei. Injury to the mammillary bodies or fornix elicits navigation deficits and spatial delayed-alteration task difficulties in several experimental models (25-29). Head direction and angular velocity cells that are distributed in multiple forebrain and midbrain areas (30-33), including the lateral MB nuclei (34), help encode spatial navigation information. Lateral MB nuclei also play significant roles in spatial memory tasks, as indicated by oxidative metabolic studies (35). Discharge of neurons within the medial MB nuclei synchronizes with the hippocampal theta rhythm, and may contribute to memory function $(36,37)$. Although MRI procedures used here were inadequate to separate lateral and medial portions of the structures, the overall volume loss in the mammillary bodies suggests the damage would contribute to impaired spatial learning and memory in subjects with CCHS.

Although the primary role of the mammillary bodies appears to be related to memory functions, the interconnections of these structures with other limbic areas may contribute to mood regulation. A significant inverse correlation emerged between Beck Depression Inventory scores and MB volumes in a combined group of heart failure and control subjects (21). Although we do not have depression scores for the subjects with CCHS, such depression signs have been described (4), and may stem partially from the MB injury.

$M B$ and fornix correlations. Left MB volumes significantly positively correlated with age in both CCHS and control groups, and left fornix cross-sectional areas showed a significant correlation with age in control subjects. The correlation of MB volume and fornix cross-sectional area with development appears preferentially on the left side. The basis for those correlations are unclear but may represent an additional example of lateralized structure and function of limbic structures (38).

Both left and right MB volumes positively correlated with left and right fornix cross-sectional areas, respectively, in the control group, whereas subjects with CCHS did not show such correlations. Loss of fornix fibers, resulting from hippocampal injury, likely contributed to the reduced MB volumes; however, the extent of fornix fiber loss did not directly relate to the magnitude of MB volume loss. The lack of a linear relation- 
Table 2. Mammillary body volumes and fornix cross-sectional areas in CCHS and control subjects

\begin{tabular}{|c|c|c|c|c|}
\hline Brain structure & Side & $\mathrm{CCHS}[\mathrm{n}=14]$ & Control $[\mathrm{n}=31]$ & ${ }^{*} p$ values \\
\hline \multirow[t]{2}{*}{ Mammillary body $\left(\right.$ mean $\left.\pm \mathrm{SD}, \mathrm{mm}^{3}\right)$} & Left & $81.56 \pm 11.18$ & $92.35 \pm 13.19$ & $<0.001$ \\
\hline & Right & $86.02 \pm 10.69$ & $91.66 \pm 13.95$ & $<0.006$ \\
\hline \multirow[t]{2}{*}{ Fornix $\left(\right.$ mean $\left.\pm \mathrm{SD}, \mathrm{mm}^{2}\right)$} & Left & $7.36 \pm 1.33$ & $8.41 \pm 1.45$ & $<0.001$ \\
\hline & Right & $7.52 \pm 1.05$ & $8.32 \pm 1.62$ & $<0.005$ \\
\hline
\end{tabular}

$\mathrm{SD}=$ Standard deviation, $*=p$ values corrected for age, gender, and total intracranial volume.
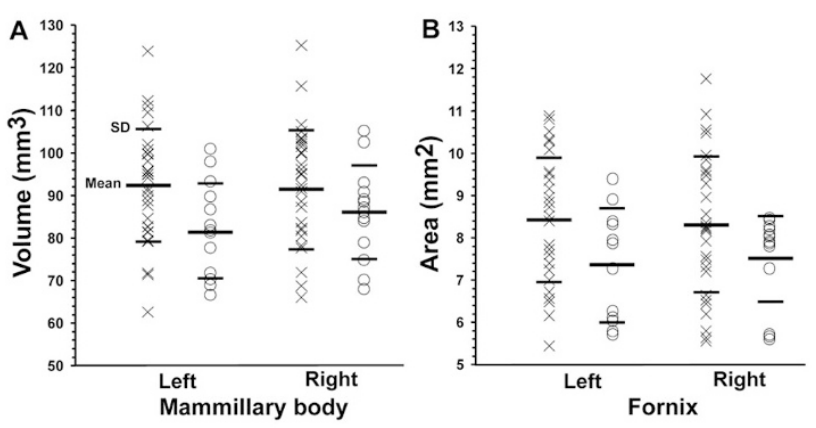

Figure 3. Individual mammillary body volumes $(A)$, and fornix crosssectional areas $(B)$, from control subjects $(\times)$ and $(\bigcirc)$ subjects with CCHS. Both mammillary body volumes and fornix cross-sectional areas are significantly reduced in subjects with CCHS over control subjects, controlling for age, gender, and total intracranial volume.

ship may arise from $\mathrm{MB}$ cell loss not directly translating to volume loss, with fluid, glia, or other replacement tissue occupying space previously filled by neurons. The nature of injury in the mammillary bodies needs to be examined on a cellular level.

Pathologic mechanisms. Although precise mechanisms of $\mathrm{MB}$ and fornix injury shown here are unknown, several possibilities emerge. Since we found that MB volumes normally positively correlate with the extent of cross-sectional area in the corresponding fornix, earlier-reported hippocampal injury in subjects with CCHS may lead to reduced fornix fibers, with consequent cell loss in the mammillary bodies. The hippocampal damage in subjects with CCHS may stem from multiple sources, including hypoxic processes accompanying hypoventilation during sleep (1). Inflammatory and oxidative processes accompany such hypoxic mechanisms, and may be especially operative here $(39,40)$. Several animal studies, simulating intermittent hypoxia of sleep-disordered breathing, found brain injury in multiple sites, including the hippocampus and other limbic areas $(39,41,42)$.

An additional possibility is that the mammillary bodies, receiving long-axon fiber projections from the hippocampus via the fibers of the fornix, may be subjected to excitotoxic injury from those fibers by hypoxia resulting from hypoventilation during sleep, in a similar fashion that Purkinje cells can be injured with hyperexcitation of climbing fibers from the inferior olive (43), and hippocampal neuronal damage can result from excessive excitation of Schaffer's collaterals during seizure discharge (44).

Thiamine roles. Mammillary body volume loss classically has been associated with conditions accompanied by thiamine (B1) and magnesium deficiency, including chronic alcoholism, beriberi, anorexia, dialysis, or other malabsorption or fluid loss conditions where inadequate absorption or flushing of nutrients may occur $(45,46)$, resulting in WernickeKorsakoffs syndrome with neuropsychological deficits, including memory deficiencies. Thiamine deficiency has also been hypothesized to underlie processes involved in the sudden infant death syndrome (47). Thiamine, together with magnesium, is an essential component of carbohydrate metabolism, and plays a critical role in neuronal survival (48), especially when cells are exposed to hypoxia (49).

Direct evidence of low thiamine levels is lacking in patients with CCHS, although profuse sweating, anecdotal reports of poor fluid intake control $(1,4)$, as well as impaired intestinal absorption, all characteristics predisposing for nutrient loss, are common complaints.

PHOX $2 B$ processes. The injury to the mammillary bodies and fornix may have derived from altered developmental processes related to the transcription factor PHOX2B, mutations of which have been implicated as leading to CCHS characteristics $(50,51)$. However, animal knockout models of PHOX2B show damage principally confined to visceral ganglia, brainstem autonomic nuclei, and chemosensitive neurons in the parafacial region $(52,53)$, which overlap neurons of the retrotrapezoid nuclei $(54,55)$. Suprabulbar structures, such as the mammillary bodies, have not been implicated as PHOX2B targets, nor are regions of the cerebellum, which are especially affected in the human condition (7). The MB volume loss may stem from secondary processes deriving from the initial PHOX2B injury, such as altered vascular development from affected autonomic ganglia, or from consequences of hypoventilation in the syndrome. The hippocampus, especially sensitive to hypoxia, is injured in subjects with CCHS (8), a consequence which could diminish the number of fornix fibers, and, in turn, MB cells. Such hypoxic injury would be exacerbated by loss of nutrient neuroprotection from fluid regulatory and visceral malabsorption aspects of the syndrome.

Limitations. We did not correlate the anatomical findings with cognitive deficits in subjects with CCHS, because the initial interest was only in anatomical findings; cognitive aspects were not part of the study. Not all subjects with CCHS show cognitive deficits, and a large range of severity emerges in those who are affected. These subjects with CCHS were recruited from the CCHS family network (http://www.cch snetwork.org), and a largely overlapping group of subjects with CCHS showed mood and cognitive deficits, including learning difficulties (4). Although the MB volume loss found here $(12 \%)$ is not as extensive as with other conditions with memory deficits $(20,21)$, the decline is close to that found in chronic alcoholics (18\%) who show significant correlations $(r=0.55)$ of bilateral MB volumes and short-retention recall scores, even when amnesia is not a principal characteristic (56). We speculate, based on data from other syndromes with 
reduced MB volumes (chronic alcoholism, beriberi, and anorexia), that the tissue loss in these sites contributes to cognitive and mood deficits.

In conclusion, $\mathrm{MB}$ volumes and fornix cross-sectional areas were significantly reduced in CCHS subjects, when compared with control subjects. Mammillary body and fornix injury may contribute to mood, learning, and memory deficits found in subjects with CCHS; however, future studies will be necessary to correlate the extent of cognitive deficits to structural findings. Hypoxic processes, along with micronutrient deficiencies, such as diminished thiamine and magnesium levels resulting from malabsorption and altered fluid regulation, may contribute to the tissue injury.

Acknowledgments. We thank Ms. Rebecca Harper and Ms. Annaise Magliore for assistance with data collection, and parents and children for participating in this study.

\section{REFERENCES}

1. 1999 Idiopathic congenital central hypoventilation syndrome: diagnosis and management. American Thoracic Society. Am J Respir Crit Care Med 160:368-373

2. Haddad GG, Mazza NM, Defendini R, Blanc WA, Driscoll JM, Epstein MA, Epstein RA, Mellins RB 1978 Congenital failure of automatic control of ventilation, gastrointestinal motility and heart rate. Medicine (Baltimore) 57:517-526

3. Paton JY, Swaminathan S, Sargent CW, Keens TG 1989 Hypoxic and hypercapnic ventilatory responses in awake children with congenital central hypoventilation syndrome. Am Rev Respir Dis 140:368-372

4. Vanderlaan M, Holbrook CR, Wang M, Tuell A, Gozal D 2004 Epidemiologic survey of 196 patients with congenital central hypoventilation syndrome. Pediatr Pulmonol 37:217-229

5. Ruof H, Hammer J, Tillmann B, Ghelfi D, Weber P 2008 Neuropsychological, behavioral, and adaptive functioning of Swiss children with congenital central hypoventilation syndrome. J Child Neurol 23:1254-1259

6. Kumar R, Macey PM, Woo MA, Alger JR, Harper RM 2006 Elevated mean diffusivity in widespread brain regions in congenital central hypoventilation syndrome. J Magn Reson Imaging 24:1252-1258

7. Kumar R, Macey PM, Woo MA, Alger JR, Harper RM 2008 Diffusion tensor imaging demonstrates brainstem and cerebellar abnormalities in congenital central hypoventilation syndrome. Pediatr Res 64:275-280

8. Kumar R, Macey PM, Woo MA, Alger JR, Keens TG, Harper RM 2005 Neuroanatomic deficits in congenital central hypoventilation syndrome. J Comp Neurol 487:361-371

9. Harper RM, Macey PM, Woo MA, Macey KE, Keens TG, Gozal D, Alger JR 2005 Hypercapnic exposure in congenital central hypoventilation syndrome reveals CNS respiratory control mechanisms. J Neurophysiol 93:1647-1658

10. Macey PM, Woo MA, Macey KE, Keens TG, Saeed MM, Alger JR, Harper RM 2005 Hypoxia reveals posterior thalamic, cerebellar, midbrain, and limbic deficits in congenital central hypoventilation syndrome. J Appl Physiol 98:958-969

11. Woo MA, Macey PM, Macey KE, Keens TG, Woo MS, Harper RK, Harper RM 2005 FMRI responses to hyperoxia in congenital central hypoventilation syndrome. Pediatr Res 57:510-518

12. Macey PM, Macey KE, Woo MA, Keens TG, Harper RM 2005 Aberrant neural responses to cold pressor challenges in congenital central hypoventilation syndrome. Pediatr Res 57:500-509

13. Lavenex PB, Amaral DG, Lavenex P 2006 Hippocampal lesion prevents spatial relational learning in adult macaque monkeys. J Neurosci 26:4546-4558

14. Ridley RM, Baker HF, Mills DA, Green ME, Cummings RM 2004 Topographical memory impairments after unilateral lesions of the anterior thalamus and contralateral inferotemporal cortex. Neuropsychologia 42:1178-1191

15. Aggleton JP, Brown MW 1999 Episodic memory, amnesia, and the hippocampalanterior thalamic axis. Behav Brain Sci 22:425-444

16. Aggleton JP, Vann SD, Saunders RC 2005 Projections from the hippocampal region to the mammillary bodies in macaque monkeys. Eur J Neurosci 22:2519-2530

17. Shibata H 1992 Topographic organization of subcortical projections to the anterior thalamic nuclei in the rat. J Comp Neurol 323:117-127

18. Victor M, Adams RD, Collins GH 1989 The Wernicke-Korsakoff Syndrome and Related Neurologic Disorders Due to Alcoholism and Malnutrition. 2nd ed. FA Davis, Philadelphia

19. Copenhaver BR, Rabin LA, Saykin AJ, Roth RM, Wishart HA, Flashman LA, Santulli RB, McHugh TL, Mamourian AC 2006 The fornix and mammillary bodies in older adults with Alzheimer's disease, mild cognitive impairment, and cognitive complaints: a volumetric MRI study. Psychiatry Res 147:93-103

20. Kumar R, Birrer BV, Macey PM, Woo MA, Gupta RK, Yan-Go FL, Harper RM 2008 Reduced mammillary body volume in patients with obstructive sleep apnea. Neurosci Lett 438:330-334
21. Kumar R, Woo MA, Birrer BV, Macey PM, Fonarow GC, Hamilton MA, Harper RM 2009 Mammillary bodies and fornix fibers are injured in heart failure. Neurobiol Dis 33:236-242

22. Harper C 2009 The neuropathology of alcohol-related brain damage. Alcohol Alcohol 44:136-140

23. Rorden C, Karnath HO, Bonilha L 2007 Improving lesion-symptom mapping. J Cogn Neurosci 19:1081-1088

24. Ashburner J, Friston KJ 2005 Unified segmentation. Neuroimage 26:839-851

25. Holmes EJ, Jacobson S, Stein BM, Butters N 1983 Ablations of the mammillary nuclei in monkeys: effects on postoperative memory. Exp Neurol 81:97-113

26. Irle E, Markowitsch HJ 1982 Single and combined lesions of the cats thalamic mediodorsal nucleus and the mamillary bodies lead to severe deficits in the acquisition of an alternation task. Behav Brain Res 6:147-165

27. Rosenstock J, Field TD, Greene E 1977 The role of mammillary bodies in spatia memory. Exp Neurol 55:340-352

28. Vann SD, Aggleton JP 2003 Evidence of a spatial encoding deficit in rats with lesions of the mammillary bodies or mammillothalamic tract. J Neurosci 23:35063514

29. Whishaw IQ, Maaswinkel H 1998 Rats with fimbria-fornix lesions are impaired in path integration: a role for the hippocampus in "sense of direction." J Neurosci 18:3050-3058

30. Blair HT, Sharp PE 1995 Anticipatory head direction signals in anterior thalamus: evidence for a thalamocortical circuit that integrates angular head motion to compute head direction. J Neurosci 15:6260-6270

31. Leutgeb S, Ragozzino KE, Mizumori SJ 2000 Convergence of head direction and place information in the CA1 region of hippocampus. Neuroscience 100:11-19

32. Sharp PE, Tinkelman A, Cho J 2001 Angular velocity and head direction signals recorded from the dorsal tegmental nucleus of gudden in the rat: implications for path integration in the head direction cell circuit. Behav Neurosci 115:571-588

33. Taube JS 1998 Head direction cells and the neurophysiological basis for a sense of direction. Prog Neurobiol 55:225-256

34. Blair HT, Cho J, Sharp PE 1998 Role of the lateral mammillary nucleus in the rat head direction circuit: a combined single unit recording and lesion study. Neuron 21:1387-1397

35. Conejo NM, Gonzalez-Pardo H, Vallejo G, Arias JL 2004 Involvement of the mammillary bodies in spatial working memory revealed by cytochrome oxidase activity. Brain Res 1011:107-114

36. Bland BH, Konopacki J, Kirk IJ, Oddie SD, Dickson CT 1995 Discharge patterns of hippocampal theta-related cells in the caudal diencephalon of the urethananesthetized rat. J Neurophysiol 74:322-333

37. Kirk IJ, Oddie SD, Konopacki J, Bland BH 1996 Evidence for differential control of posterior hypothalamic, supramammillary, and medial mammillary thetarelated cellular discharge by ascending and descending pathways. J Neurosci 16:5547-5554

38. Oppenheimer SM, Gelb A, Girvin JP, Hachinski VC 1992 Cardiovascular effects of human insular cortex stimulation. Neurology 42:1727-1732

39. Veasey SC, Davis CW, Fenik P, Zhan G, Hsu YJ, Pratico D, Gow A 2004 Long-term intermittent hypoxia in mice: protracted hypersomnolence with oxidative injury to sleep-wake brain regions. Sleep 27:194-201

40. Zhan G, Fenik P, Pratico D, Veasey SC 2005 Inducible nitric oxide synthase in long-term intermittent hypoxia: hypersomnolence and brain injury. Am J Respir Cri Care Med 171:1414-1420

41. Gozal D, Daniel JM, Dohanich GP 2001 Behavioral and anatomical correlates of chronic episodic hypoxia during sleep in the rat. J Neurosci 21:2442-2450

42. Pae EK, Chien P, Harper RM 2005 Intermittent hypoxia damages cerebellar cortex and deep nuclei. Neurosci Lett 375:123-128

43. Welsh JP, Yuen G, Placantonakis DG, Vu TQ, Haiss F, O’Hearn E, Molliver ME, Aicher SA 2002 Why do Purkinje cells die so easily after global brain ischemia? Aldolase C, EAAT4, and the cerebellar contribution to posthypoxic myoclonus. Adv Neurol 89:331-359

44. Ang CW, Carlson GC, Coulter DA 2006 Massive and specific dysregulation of direct cortical input to the hippocampus in temporal lobe epilepsy. J Neurosci $26: 11850$ 11856

45. Harper C 2006 Thiamine (vitamin B1) deficiency and associated brain damage is still common throughout the world and prevention is simple and safe! Eur $\mathbf{J}$ Neurol 13:1078-1082

46. Kornreich L, Bron-Harlev E, Hoffmann C, Schwarz M, Konen O, Schoenfeld T, Straussberg R, Nahum E, Ibrahim AK, Eshel G, Horev G 2005 Thiamine deficiency in infants: MR findings in the brain. AJNR Am J Neuroradiol 26:1668-1674

47. Read DJ 1978 The aetiology of the sudden infant death syndrome: current ideas on breathing and sleep and possible links to deranged thiamine neurochemistry. Aust N Z J Med 8:322-336

48. Singleton CK, Martin PR 2001 Molecular mechanisms of thiamine utilization. Curr Mol Med 1:197-207

49. Shin BH, Choi SH, Cho EY, Shin MJ, Hwang KC, Cho HK, Chung JH, Jang Y 2004 Thiamine attenuates hypoxia-induced cell death in cultured neonatal rat cardiomyocytes. Mol Cells 18:133-140 
50. Amiel J, Laudier B, Attie-Bitach T, Trang H, de Pontual L, Gener B, Trochet D Etchevers H, Ray P, Simonneau M, Vekemans M, Munnich A, Gaultier C, Lyonnet S 2003 Polyalanine expansion and frameshift mutations of the pairedlike homeobox gene PHOX2B in congenital central hypoventilation syndrome. Nat Genet 33:459-461

51. Weese-Mayer DE, Berry-Kravis EM, Ceccherini I, Rand CM 2008 Congenital central hypoventilation syndrome (CCHS) and sudden infant death syndrome (SIDS): kindred disorders of autonomic regulation. Respir Physiol Neurobiol $164: 38-48$

52. Dauger S, Pattyn A, Lofaso F, Gaultier C, Goridis C, Gallego J, Brunet JF 2003 Phox $2 \mathrm{~b}$ controls the development of peripheral chemoreceptors and afferent visceral pathways. Development 130:6635-6642
53. Dubreuil V, Ramanantsoa N, Trochet D, Vaubourg V, Amiel J, Gallego J, Brunet JF, Goridis C 2008 A human mutation in Phox2b causes lack of CO2 chemosensitivity, fatal central apnea, and specific loss of parafacial neurons. Proc Natl Acad Sci USA 105:1067-1072

54. Stornetta RL, Moreira TS, Takakura AC, Kang BJ, Chang DA, West GH, Brunet JF, Mulkey DK, Bayliss DA, Guyenet PG 2006 Expression of Phox2b by brainstem neurons involved in chemosensory integration in the adult rat. J Neurosci 26:10305-10314

55. Onimaru H, Ikeda K, Kawakami K 2008 CO2-sensitive preinspiratory neurons of the parafacial respiratory group express Phox $2 b$ in the neonatal rat. $J$ Neurosci 28:12845-12850

56. Sullivan EV, Lane B, Deshmukh A, Rosenbloom MJ, Desmond JE, Lim KO, Pfefferbaum A 1999 In vivo mammillary body volume deficits in amnesic and nonamnesic alcoholics. Alcohol Clin Exp Res 23:1629-1636 